\section{A) Check for updates}

Cite this: Org. Chem. Front., 2020, 7, 1895

Received 22nd April 2020, Accepted 23rd June 2020

DOI: $10.1039 / \mathrm{d} 0$ qo00486c

rsc.li/frontiers-organic

\title{
Recent advances in photoelectrochemical cells (PECs) for organic synthesis
}

\author{
Yan-Chen $\mathrm{Wu}^{\mathrm{a}}{ }^{\mathrm{R}}$ Ren-Jie Song (D) *a and Jin-Heng Li (D)*a,b
}

Photoelectrochemical cells (PECS) have emerged as an environmentally friendly tool for fuel production, conversion of carbon dioxide, water splitting, and pollutant degradation in the past few years. Although PECs show advantages in these areas, their application in organic synthesis has just begun. Recently, oxidation, $\mathrm{C}-\mathrm{H}$ functionalization and cross-coupling have been successfully achieved in PECs by the use of an oxidizing photoanode, such as $\mathrm{BiVO}_{4}$ or $\mathrm{WO}_{3}$, for the construction of $\mathrm{C}-\mathrm{N}, \mathrm{C}-\mathrm{O}$ and $\mathrm{C}-\mathrm{P}$ bonds. This highlight article focuses on the application of PECs in organic synthesis reactions and their reaction mechanisms, with a special emphasis on enantioselective conversions.

\section{Introduction}

The effective transformation of sunlight into chemical fuel and energy has continuously attracted the attention of chemists because sunlight is an inexpensive, abundant, non-polluting, and endlessly renewable source of clean energy. ${ }^{1}$ As a consequence, the development of green and effective methods for this conversion is an attractive research area in energy chemistry, synthetic chemistry and materials chemistry.

Since the first photoelectrochemical cells (PECs) were reported in 1972, PEC-based solar water splitting was the most studied path in this promising area. ${ }^{2}$ As research progressed, scientists found that the potential of PECs was not limited to this simple field, and other applications of PECs were reported. Their applications were expanded to the fields of fuel production, conversion of carbon dioxide, and pollutant degradation. ${ }^{3,4}$ However, their application in organic synthesis was limited. Recently, much effort has been made to develop systems for this transformation through the use of numerous photoanode materials. Various oxidizing photoanodes, such as $\mathrm{BiVO}_{4}$ and $\mathrm{WO}_{3}$, have been used to realize organic redox reactions. ${ }^{5}$ Different reaction types, such as the oxidation of simple substrates, $\mathrm{C}-\mathrm{H}$ functionalization and $\mathrm{R}^{1}-\mathrm{H} / \mathrm{R}^{2}-\mathrm{H}$ cross coupling reactions, have been successfully achieved in PEC cell systems (Scheme 1). This organic transfer system in PEC cells has become a powerful strategy for the construction of high value-added chemicals, which has emerged as an atom-economical, environmentally-friendly, and energy saving method in organic chemistry.

\footnotetext{
${ }^{a}$ Key Laboratory of Jiangxi Province for Persistent Pollutants Control and Resources Recycle, Nanchang Hangkong University, Nanchang 330063, China

${ }^{b}$ State Key Laboratory of Chemo/Biosensing and Chemometrics, Hunan University, Changsha 410082, China.E-mail: srj0731@hnu.edu.cn, jhli@hnu.edu.cn
}

Similarly to traditional photochemistry and electrochemistry, ${ }^{6,7}$ photoelectrochemistry is an environmentally friendly synthetic tool. Compared with these methods, the most obvious advantage of chemical reactions in PECs is the reduction of external bias, thereby saving electricity. Notably, organic system reactions in PECs mostly work under metal-free and chemical oxidant-free conditions, which will become an ideal research direction. With the use of a photoanode as the electrode material, the use of external power can be avoided and the applied voltage can be decreased. At present, PEC cells have no obvious advantage regarding the control of reactivity and selectivity. Organic transformation in PECs may avoid excessive oxidation and reduce side reactions to obtain better chemical selectivity due to lower external bias. We hope that these problems can be solved by designing different photoanode materials (doped with transition metal catalysts) in the future.

This highlight article aims to provide a concise overview of organic synthesis in photoelectrochemical cells for the formation of different chemical bonds and also emphasizes

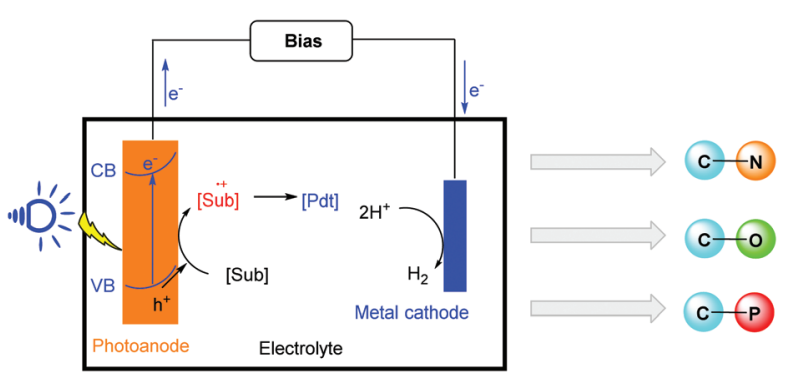

Scheme 1 Photoelectrochemical cells (PECs) for oxidative transformations of organic substrates. 
transformation pathways. The advantages and shortcomings of photoelectrochemical organic reactions using PEC cells are also discussed.

\section{Photoelectrochemical simple oxidation in PEC cells}

5-Hydroxymethylfurfural (HMF) is a key intermediate in biomass conversion, and 2,5-furandicarboxylic acid (FDCA) is an important monomer for the production of numerous polymer materials. Much effort has been made to achieve the conversion of HMF into FDCA. Although the methods are efficient, the requirements for transition-metal catalysts, highpressure $\mathrm{O}_{2}$ or air (3-20 bar), an alkaline aqueous solution ( $\mathrm{pH}$ $\geq 13$ ), and elevated temperatures $\left(30-130{ }^{\circ} \mathrm{C}\right)$ are drawbacks, which limit the applications of this transformation. ${ }^{8}$ Thus, it is attractive to find a mild, efficient synthetic strategy to complete this valuable transformation.

In 2015, Choi's group reported a TEMPO-mediated electrooxidative reaction of HMF for the synthesis of FDCA in a photoelectrochemical cell (Scheme 2a). ${ }^{9}$ Utilizing an n-type $\mathrm{BiVO}_{4}$ material as the oxidation photoanode and a platinum plate as the reduction cathode in the presence of TEMPO as a mediator, HMF can convert into FDCA with a near-quantitative yield and $100 \%$ faradaic efficiency at ambient conditions without the use of precious-metal catalysts. Meanwhile, the authors also demonstrated a novel strategy using PECs which utilizes solar energy for HMF oxidation as the anode reaction (Scheme 2b). The results suggest that PECs can not only be used for fuel production, but can also be used in producing high value-added chemicals from simple organic substrates by photoanode oxidation processes. More importantly, by using photogenerated holes in the $\mathrm{VB}$ of $\mathrm{BiVO}_{4}$ for oxidation, a lower
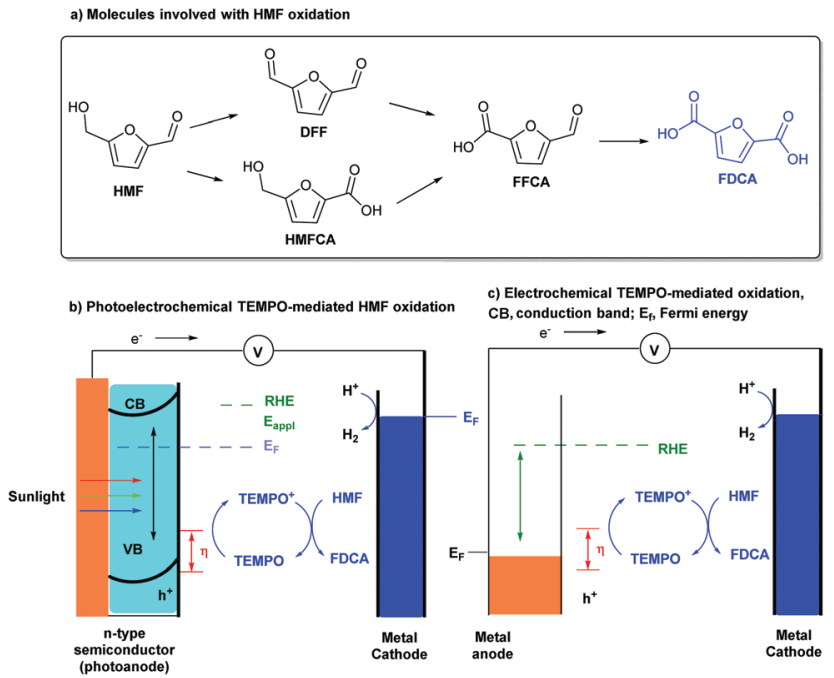

Scheme 2 Schematic comparison of photoelectrochemical and electrochemical cells. applied potential could be used for TEMPO oxidation, which is about $0.1 \mathrm{~V}$ versus RHE.

Subsequently, organic transformation in photoelectrochemical cells has attracted a great deal of interest in organic synthetic chemistry because it avoids using expensive and toxic reagents or catalysts. In 2017, Sammis, Berlinguette and coworkers realized a photoelectrochemical alcohol oxidation and $\mathrm{C}-\mathrm{H}$ functionalization in $\mathrm{PEC}$ cells. Employing a $\mathrm{BiVO}_{4}$ electrode as the photoanode, MeCN as the solvent, and NHPI as the electron transfer reagent, benzyl alcohol, cyclohexene and 1,2,3,4-tetrahydronaphthalene could furnish the corresponding ketones in moderate to good yields (Scheme 3). ${ }^{10}$ Compared with traditional chemical oxidation conditions, this method avoids the use of other additives, such as metal catalysts and strong oxidants, which may cause pollution problems. Moreover, this photoelectrochemical oxidative reaction was accomplished by using sunlight as the single energy source, which can reduce the applied voltage of an EC oxidation process by $1 \mathrm{~V}$. Importantly, the results of the experiments showed that NHPI was necessary for this photoelectrochemical system.

Sayama and co-workers also successfully achieved a similar photoelectrochemical oxidation of benzylic alcohol derivatives on $\mathrm{BiVO}_{4} / \mathrm{WO}_{3}$ under visible light irradiation (Scheme 4). ${ }^{11 a}$ Employing a $\mathrm{BiVO}_{4} / \mathrm{WO}_{3}$ composite photoelectrode in aprotic organic media, the oxidation reaction proceeded smoothly and generated the corresponding ketones in up to $97 \%$ yield. The recyclability of this electrode material was also examined and the composite $\mathrm{BiVO}_{4} / \mathrm{WO}_{3}$ photoelectrode could be used at least three times for the photoelectrochemical oxidation of alcohols. It was noted that the TON of products to $\mathrm{BiVO}_{4}$ was approximately 1200 .

A similar simple oxidant reaction was reported by Yehezkeli, Goodwin, Cha and co-workers in the same year. ${ }^{11 b}$ They achieved the transformation from $n$-butanol to 2-ethylhexenal by tandem enzymatic oxidation and aldol condensation in a PEC system by employing $\mathrm{BiVO}_{4}$ as the anode material.

Direct $\mathrm{C}-\mathrm{H}$ activation reactions have attracted widespread attention in organic synthesis because this reaction can often improve the atom- and step economies. Over the past decades, many fascinating methods have been developed, including transition-metal-catalyzed $\mathrm{C}-\mathrm{H}$ activation and electrochemical

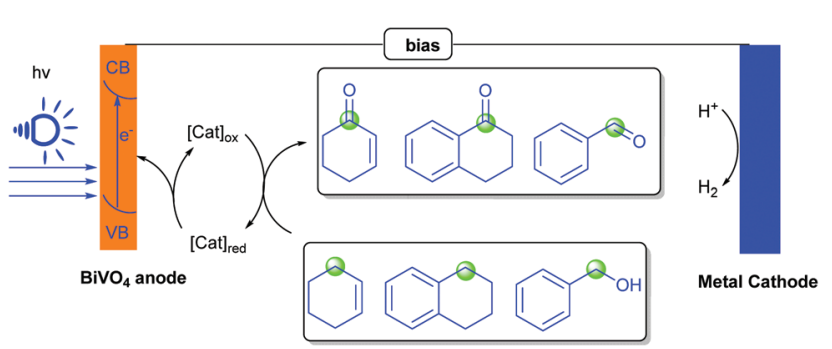

Scheme 3 PEC cells for oxidation of organic substrates in organic media. 

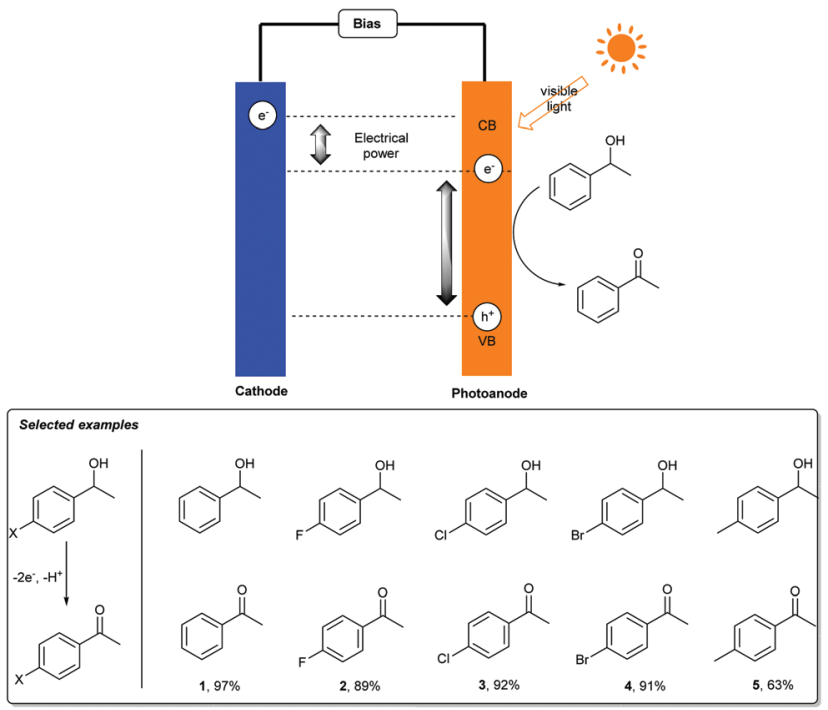

Scheme 4 The photo-assisted electrochemical oxidation of benzylic alcohol derivatives and the proposed reaction mechanism.

$\mathrm{C}-\mathrm{H}$ activation. ${ }^{12}$ In order to achieve specific reactivity for $\mathrm{C}-\mathrm{H}$ activation under mild conditions, Sayama's group also developed a novel photo-electrochemical $\mathrm{C}-\mathrm{H}$ bond activation reaction of cyclohexane using a $\mathrm{WO}_{3}$ photoanode and visible light in air at room temperature and atmospheric pressure (Scheme 5). ${ }^{13}$ The oxidation ability of $\mathrm{h}^{+}$at the valence band potential of $\mathrm{WO}_{3}$ is almost identical to that of $\mathrm{TiO}_{2}(+3.1 \mathrm{~V} v s$. $\mathrm{RHE}$ ), and the conduction band potential of $\mathrm{WO}_{3}$ is $+0.5 \mathrm{~V} v s$. RHE. In this strategy, excellent partial oxidation selectivity up to $99 \%$ and apparent faradaic efficiency (76\%) were obtained and the IPCE at 365 and $420 \mathrm{~nm}$ were $57 \%$ and $24 \%$, respectively.

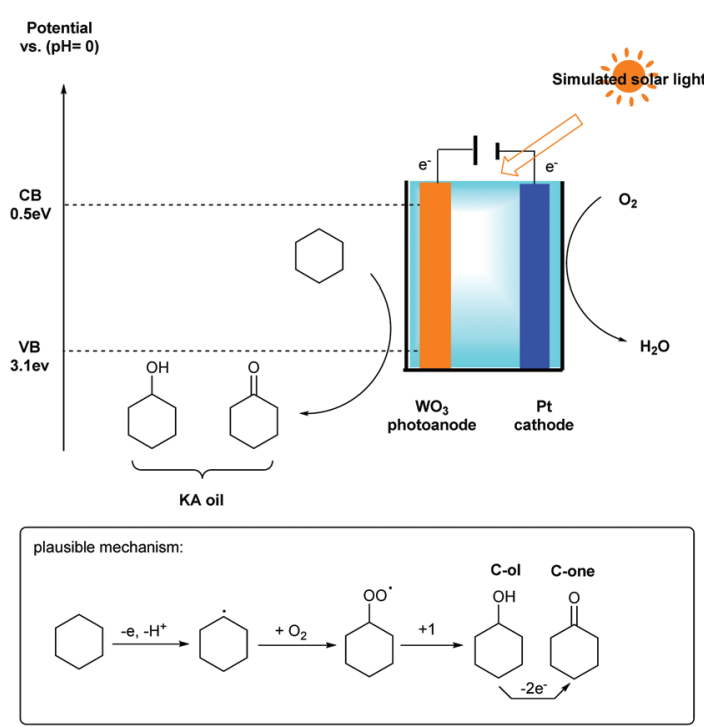

Scheme 5 PEC cells for $\mathrm{C}-\mathrm{H}$ bond activation of cyclohexane.
A possible mechanism was also proposed in scheme 5 . Firstly, the single-electron transfer process of cyclohexane by the photoanode affords the cyclohexyl radical through $\mathrm{C}-\mathrm{H}$ bond cleavage. Then the cyclohexyl radical is activated by $\mathrm{O}_{2}$ to give a cyclohexylperoxyl radical. Finally, the cyclohexylperoxyl radical is disproportionately transformed to the corresponding products cyclohexanol and cyclohexanone. Cyclohexanol can further convert to cyclohexanone via an additional two-electron oxidation process. However, another byproduct, namely dicyclohexyl, was often detected by coupling of a cyclohexyl radical in the absence of $\mathrm{O}_{2}$.

A peroxygenase catalyzed oxyfunctionalization of $\mathrm{C}-\mathrm{H}$ bonds through photoelectrochemical $\mathrm{H}_{2} \mathrm{O}_{2}$ generation in PEC cells was successfully demonstrated by the Park group in 2019, in which $\mathrm{FeOOH} / \mathrm{BiVO}_{4}$ was used as the photoanode, $\mathrm{CN} / \mathrm{rGO}$ as the cathode and CIGS as the solar cell. ${ }^{14}$ It was noted that they also successfully achieved photoelectroenzymatic hydroxylation of ethylbenzene to give (R)-1-phenylethanol with a TTN of 43300 and up to $99 \%$ ee via this system.

Substituted furans are found as structural units in many natural products and bioactive molecules, while they are also important synthetic intermediates in organic synthesis. ${ }^{15}$ New and green synthetic investigations of furan derivatives have continuously attracted the attention of many organic chemists. In 2017, Sayama's group reported a selective photoelectrochemical dimethoxylation reaction between furan and $\mathrm{MeOH}$ by using a composite n-type semiconductor $\mathrm{BiVO}_{4} / \mathrm{WO}_{3}$ photoanode and $\mathrm{Br}^{+} / \mathrm{Br}^{-}$as a mediator, with excellent faradaic efficiency up to $99 \%$ (Scheme 6). ${ }^{16}$ The utilization of photoelectrochemistry instead of an electrochemical method under dark conditions tactfully addressed the challenge of avoiding side reactions, such as the oxidation of $\mathrm{MeOH}$ and the methoxylated product. In addition, the applied potential in this system could be decreased by using solar energy. In order to prove that photoelectrolysis is a useful method for decreasing the applied potential, they tested the oxidation potential under dark and photoirradiation conditions, respectively. In the case of the $\mathrm{BiVO}_{4} / \mathrm{WO}_{3}$ photoelectrode, the oxidation potential shifted from $1.2 \mathrm{~V}$ to $0 \mathrm{~V} v$ s. SHE under photoirradiation. The bromide ion plays an important role in the transformation

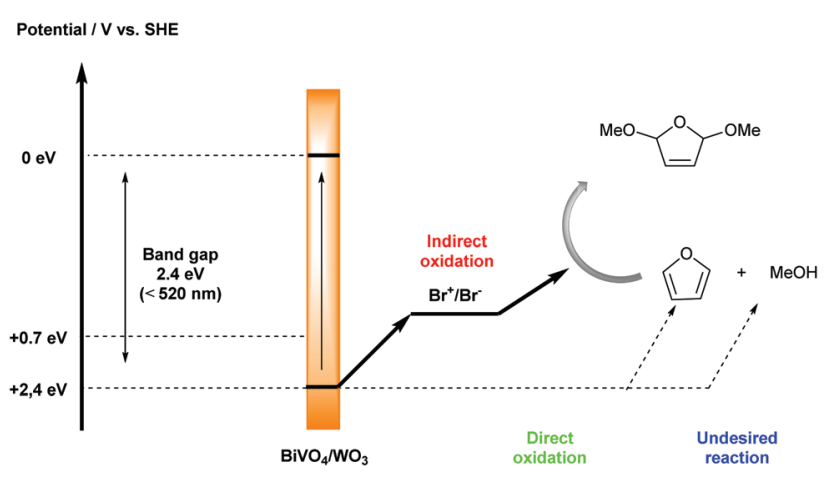

Scheme 6 Plausible mechanism for photoelectrochemical dimethoxylation of furan with $\mathrm{Br}^{+} / \mathrm{Br}^{-}$as a mediator. 
process; only a trace amount of product was detected in the absence of $\mathrm{Et}_{4} \mathrm{NBr}$ as a $\mathrm{Br}^{-}$source. The addition of $\mathrm{Et}_{4} \mathrm{NBF}_{4}$ as a co-supporting electrolyte also improved the efficiency of the dimethoxylation.

\section{Photoelectrochemical $\mathrm{C}-\mathrm{H}$ functionalization and $\mathrm{R}^{1}-\mathrm{H} / \mathrm{R}^{2}-\mathrm{H}$ cross coupling in PEC cells}

Electrochemical organic synthesis methods have been recognized as some of the most environmentally friendly pathways for producing high value-added organic compounds. ${ }^{17}$ Recently, photoelectrochemical cells, an environmentally friendly synthetic tool, have been used to achieve the oxidation of simple substrates. Despite the conceptual advance, only simple organic substrates have been tested in PEC cell systems. The conversion of broad-scope organic molecules by the utilization of PEC cells is still a challenge.

Recently, $\mathrm{Hu}$ and co-workers successfully realized a novel photoelectrocatalytic $\mathrm{C}-\mathrm{H}$ amination of arenes and pyrazoles (Scheme 7). ${ }^{18}$ In this reaction, a haematite photoanode was used as the electrode due to its low cost, high stability and suitable bandgap of $2.1 \mathrm{eV}$ for strong visible light absorption; compared to organic photoredox catalysts, such as acridinium, haematite (2.3 V versus the standard hydrogen electrode) has a similar oxidation potential, which suggests similar reactivity. Using $\mathrm{LiClO}_{4}$ as the supporting electrolyte, HFPI/MeOH $(4: 1)$ as the co-solvent, and blue LED as the light source, various arenes could be converted to the corresponding substituted $\mathrm{N}$-heterocycle products in up to $89 \%$ yield.

A plausible mechanism was also proposed by the authors; see Scheme 8. Unusual ortho selectivity was observed, possibly due to the formation of intermediate $\mathbf{A}$, which possessed a hydrogen bond between hexafluoroisopropanol and pyrazole. Compared with the photoredox catalysed $\mathrm{C}-\mathrm{H} / \mathrm{N}-\mathrm{H}$ cross coupling reaction, this method showed a different mechanism. The
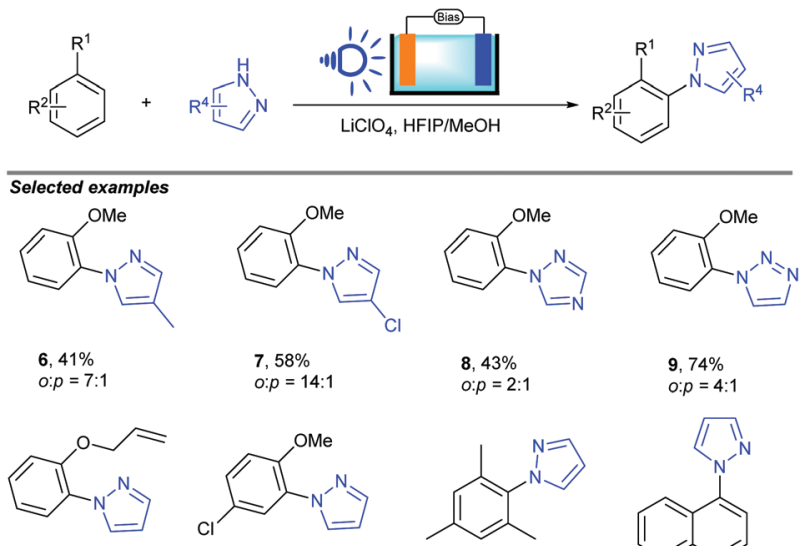

10. $56 \%$

$11,56 \%$

12. $50 \%$

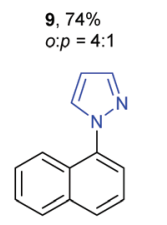

$13,62 \%$

Scheme 7 PEC cells for $\mathrm{C}-\mathrm{H}$ amination of arenes.

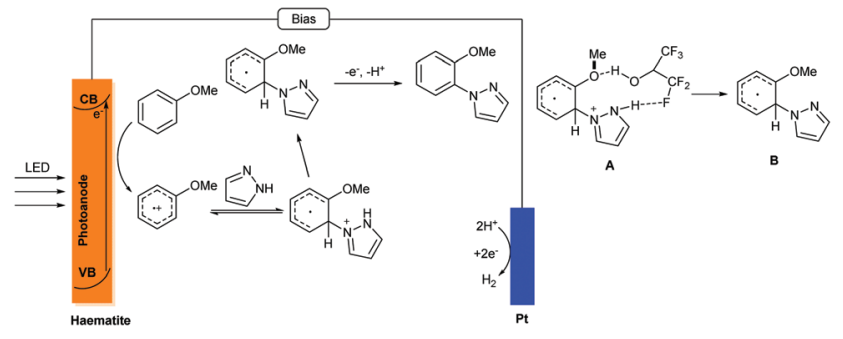

Scheme 8 Possible mechanism of this photo-electrochemical $\mathrm{C}-\mathrm{H}$ amination.

photogenerated redox process was localized in the valence band (VB) of the haematite photoanode and the PECs absorbed the light using a heterogeneous haematite semiconductor. It is worth noting that the charge in this photoelectrochemical reaction was transferred from the edge of the VB to the substrate for oxidation, which was different from the electrochemical reaction.

Organophosphorus compounds, especially $\alpha$-amino phosphonates, are a valuable skeleton widely present in materials chemistry, agrochemicals, and biochemistry. ${ }^{19}$ Most of the reported methods for their synthesis suffer from various disadvantages such as the need for metal catalysts, stoichiometric oxidants or directing groups. PEC cells, as a valuable electrochemical synthetic tool to save energy in organic synthesis, can solve these problems. In 2019, the $\mathrm{Wu}$ group also described an energy saving electrochemical synthesis method in PEC cells to achieve $\mathrm{P}-\mathrm{H} / \mathrm{C}-\mathrm{H}$ cross coupling with a hydrogen evolution strategy between amines and $\mathrm{P}(\mathrm{O}) \mathrm{H}$ compounds (Scheme 9). ${ }^{20}$ By using BiVO $_{4}$ as a photoanode and NHPI as a mediator, a series of organophosphorus compounds were produced in good to excellent yields with hydrogen evolution. In addition, this approach showed good functional-group tolerance and broad substrate scope. Importantly, nearly $90 \%$ external bias input was saved to achieve this conversion by the use of PEC cells as the reactor $\left(0.1 \mathrm{~V} v\right.$ s. $0.5 \mathrm{~V}$ for the $\mathrm{BiVO}_{4} \mathrm{PEC}$ system and glassy carbon EC system). Generally, chemists are considering using PEC cells to achieve organic reactions because this method can avoid energy waste. In this transformation, they successfully proved that PEC systems can considerably decrease the applied voltage for $\mathrm{C}-\mathrm{P}$ bond construction, and serve as viable methods to realize selective redox transformations under efficient and energy saving conditions through electron transfer on the electrode surface.

A plausible mechanism for the $\mathrm{P}-\mathrm{H} / \mathrm{C}-\mathrm{H}$ cross coupling reaction in PEC cells is outlined in Scheme 10. Firstly, high energy electron-hole pairs were generated from the $\mathrm{BiVO}_{4}$ photoelectrode once it was excited by the incident photons. Then, on the electrode surface, the radical cation intermediate D was formed from $\mathbf{C}$ when the holes reached the surface of $\mathrm{BiVO}_{4}$. At the same time, NHPI and 2,6-luttidine deprotonation obtained the corresponding PINO radicals by anodic oxidation, and the subsequent abstraction of a hydrogen atom (the PINO radical extracts a hydrogen atom from $\mathrm{D}$ to regenerate NHPI) 


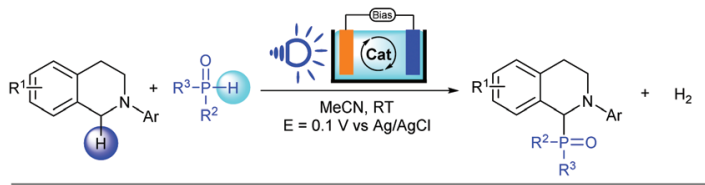

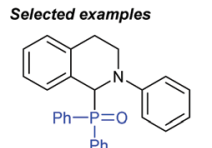

$14,90 \%$<smiles>COc1ccc(N2CCc3ccccc3C2P(=O)(c2ccccc2)c2ccccc2)cc1</smiles>

$\mathrm{Ph}$
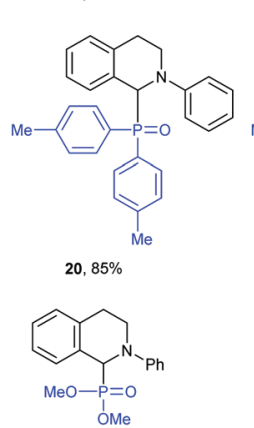

$23,81 \%$

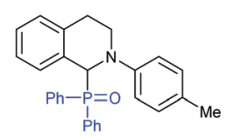

15, $90 \%$<smiles>COc1ccccc1N1CCc2ccccc2C1P(C)(=O)c1ccccc1</smiles>

$18,91 \%$
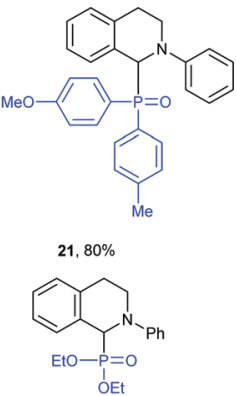

24, $70 \%$

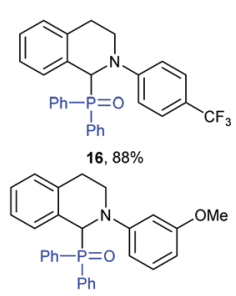

$19,86 \%$

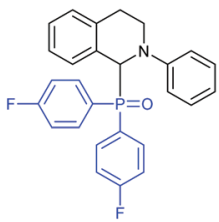

22, $72 \%$

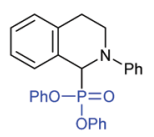

25. $75 \%$
Scheme 9 PEC cells for phosphorylation of $\mathrm{C}-\mathrm{H}$ bond.

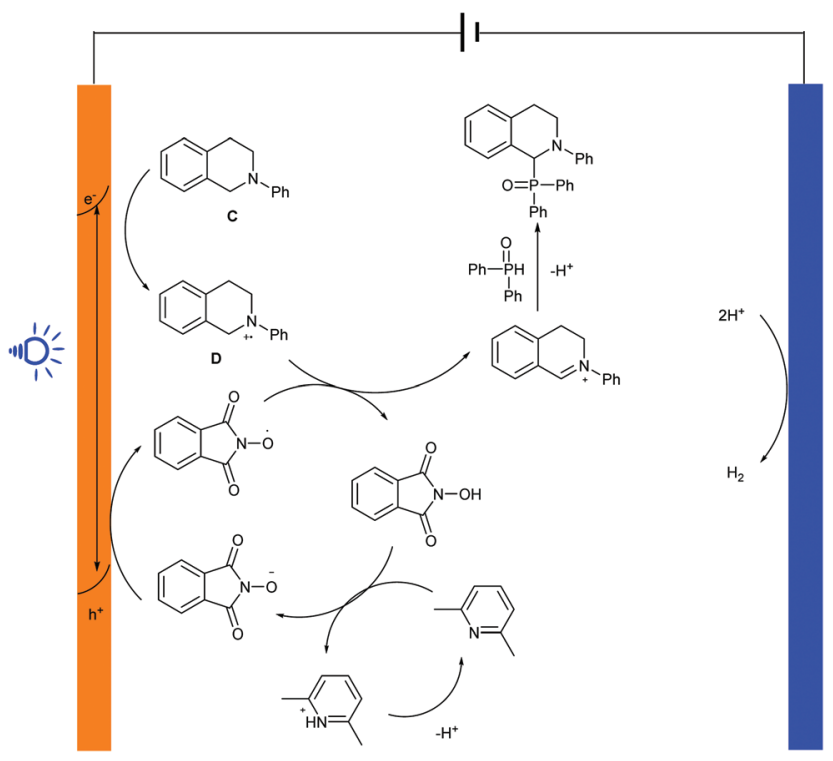

Scheme 10 The plausible mechanism for PEC cells for phosphorylation of $\mathrm{C}-\mathrm{H}$ bond.

proceeded to give the iminium ion intermediate $\mathbf{C}^{+}$, which reacted with diphenyl-phosphine oxide via nucleophilic attack to enable the formation of the final product with a C-P bond. On the cathode surface, the released protons could be reduced to release hydrogen gas during the reaction.
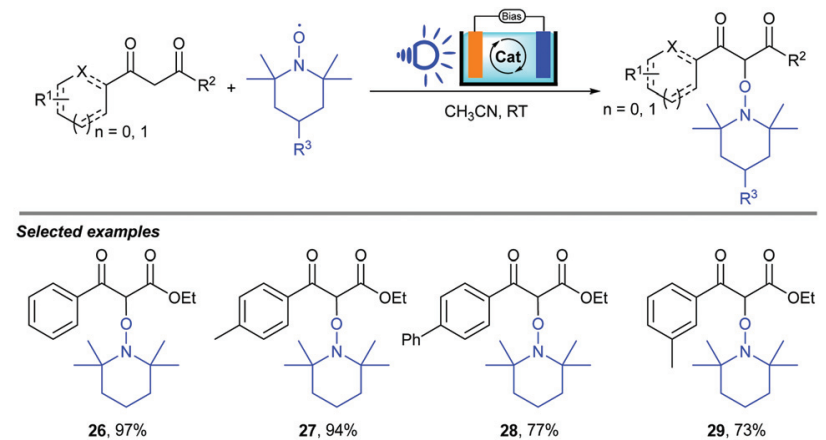

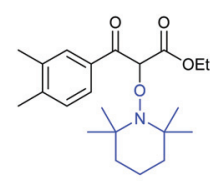

30, $87 \%$

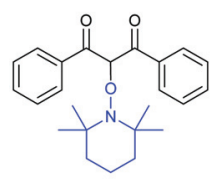

31, $74 \%$

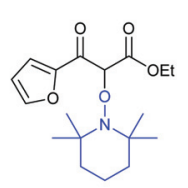

$32,92 \%$

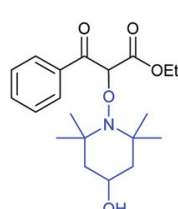

33, $52 \%$
Scheme 11 PEC cells for $\alpha$-oxyamination of 1,3-dicarbonyls.

As we know, photoelectrocatalysis occurring in dye-sensitized solar cell (DSSC) devices serves as a novel synthetic method which has successfully been used to achieve the conversion of light energy into electric and chemical energy. Recently, Huang, Wu and co-workers reported a visible-lightinduced $\alpha$-oxyamination between 1,3-dicarbonyls and TEMPO via a photo(electro)catalytic process using visible light as the energy source (Scheme 11). ${ }^{21}$ By using a DSSC anode or a DSSC system, the cross-coupling of 1,3-dicarbonyls and TEMPO occurred smoothly, leading to a series of $\alpha$-oxyaminated carbonyl compounds in good to excellent yields (32-97\%), featuring advantages such as easy separation, environmental protection, low energy consumption, and sustainability. Notably, the DSSC anode could be reused more than 8 times.

The reaction mechanism for this visible-light-induced $\alpha$-oxyamination of 1,3-dicarbonyls and TEMPO in PEC cells is shown in Scheme 12. Three different catalytic cycles with three types of catalysts (a trace amount of dissociated N719 in solution, unsensitized $\mathrm{TiO}_{2}$ film and N719-sensitized DSSC anode) were involved in the $\alpha$-oxyamination reaction between 1,3dicarbonyl and TEMPO. An excited state $\mathrm{N} 19^{*}\left[\mathrm{Ru}(\mathrm{II})^{*}\right]$ is formed from N719 under irradiation by blue light. Then, an electron is transferred from $\mathrm{N} 19^{*}$ to fill the conduction band (CB) of $\mathrm{TiO}_{2}$, which gives an oxidized $\mathrm{Ru}(\mathrm{III})$ complex. Subsequently, TEMPO is oxidized by $\mathrm{Ru}(\mathrm{III})$ to generate $\mathrm{TEMPO}^{+}(\mathbf{E})$ and the Ru(III) complex regains its ground state (N719), which undergoes single-electron transfer (SET) affording to the intermediate E. At the same time, a TEMPO anion (F) was formed with the aid of TEMPO oxidation. Moreover, the adsorption of TEMPO on the $\mathrm{TiO}_{2}$ film promotes the absorption of $\mathrm{TiO}_{2}$ under blue light. On the other hand, similarly to indirect electrolysis, TEMPO acted not only as coupling reagent but also as a catalyst in this transformation. Finally, the SET process and radical cross coupling happened to give the desired product L. Alternatively, the reaction 


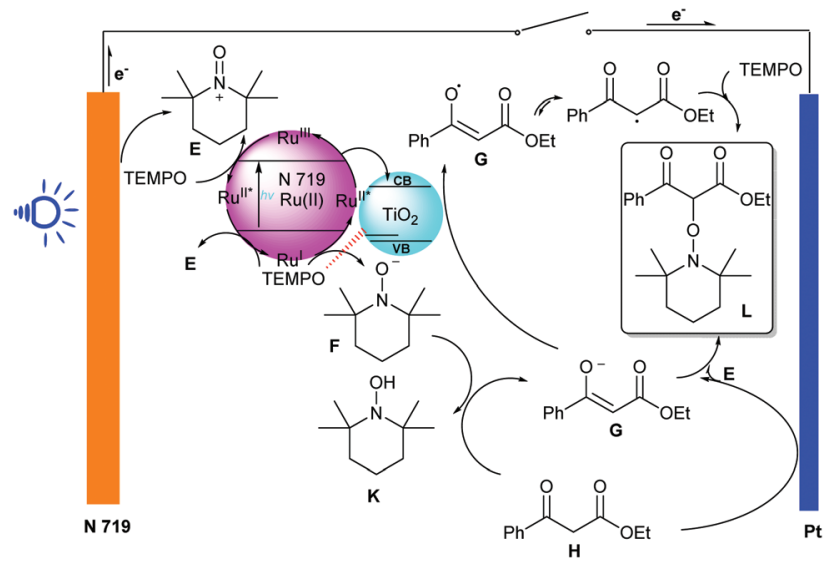

Scheme 12 The plausible mechanism for visible-light-induced $\alpha$-oxyamination of 1,3-dicarbonyls and TEMPO in PEC cells.

between the dicarbonyl anion (G) and the TEMPO cation (E) could also afford the corresponding product $\mathbf{L}$.

\section{Conclusion and outlook}

In view of the recent successful development of photoanode oxidation as a powerful tool in organic synthesis, a wide range of oxidative $\mathrm{C}-\mathrm{H} / \mathrm{X}-\mathrm{H}(\mathrm{X}=\mathrm{N}, \mathrm{O}, \mathrm{P}$, etc. $)$ cross-coupling reactions have been reported. In this highlight, we summarized recent progress in photoelectrochemical oxidative conditions in PEC cells. A wide range of efficient and green methods for directly forming $\mathrm{C}-\mathrm{N}, \mathrm{C}-\mathrm{O}$, and $\mathrm{C}-\mathrm{P}$ bonds have been developed. Generally, PEC cell photoelectrochemical systems use the oxidizing power of photoanodes, such as $\mathrm{BiVO}_{4}$ and $\mathrm{WO}_{3}$, for this transformation under metal- and chemical oxidantfree conditions. Compared with electrochemical systems, PEC systems save more energy. However, there are some limitations of the utilization of photoelectrochemical cells for organic synthesis, such as a more complex set-up, which is a major hurdle for reaction scale-up, and there is no uniform standard for the equipment. Although various photoelectrochemical organic reactions have been studied in recent years for the construction of carbon-heteroatom bonds, there are still some challenges: (i) methods for constructing carbon-carbon, other carbon-heteroatom and heteroatom-heteroatom bonds in PEC systems are relatively scarce; (ii) single electrode type and narrow substrate scope; (iii) low chemical- and region-selectivity in this transformation. Hopefully, future extensive studies of photoelectrochemical methods in PEC cells can enrich complicated reaction types by utilizing new electrode materials and/or the addition of transition metal catalysts or organic small molecule catalysts. We hope that this highlight will inspire chemists to take continued interest in the field of photoelectrochemical oxidative reactions with hydrogen evolution.

\section{Conflicts of interest}

There are no conflicts of interest.

\section{Acknowledgements}

We thank the National Natural Science Foundation of China (no. 21762030, 51878326, 21625203 and 21871126) for financial support. Ren-Jie Song was also supported by the China Scholarship Council (contract 201908360088).

\section{Notes and references}

1 (a) C. A. Grimes, O. K. Varghese and S. Ranjan, Light, Water, Hydrogen: The Solar Generation of Hydrogen by Water Photolysis, Springer Science, New York, 1st edn, 2008, pp. 1-33; (b) M. G. Walter, E. L. Warren, J. R. McKone, S. W. Boettcher, Q. X. Mi, E. A. Santori and N. S. Lewis, Solar Water Splitting Cells, Chem. Rev., 2010, 110, 6446; (c) L. Vernon, Free radical chemistry of coal liquefaction: role of molecular hydrogen, Fuel, 1980, 59, 102.

2 (a) G. Ramila and P. Erb, Accessory cell-dependent selection of specific T-cell functions, Nature, 1983, 304, 442; (b) H. M. Chen, C. K. Chen, R.-S. Liu, L. Zhang, J. Zhang and D. P. Wilkinson, Nano-architecture and material designs for water splitting photoelectrodes, Chem. Soc. Rev., 2012, 41, 5654; (c) J. R. Swierk and T. E. Mallouk, Design and development of photoanodes for water-splitting dye-sensitized photoelectrochemical cells, Chem. Soc. Rev., 2013, 42, 2357; (d) F. E. Osterloh, Inorganic nanostructures for photoelectrochemical and photocatalytic water splitting, Chem. Soc. Rev., 2013, 42, 2294; (e) M. Liras, M. Barawi and V. A. de la Peña O'Shea, Hybrid materials based on conjugated polymers and inorganic semiconductors as photocatalysts: from environmental to energy applications, Chem. Soc. Rev., 2019, 48, 5454.

3 (a) M. K. Debe, Electrocatalyst approaches and challenges for automotive fuel cells, Nature, 2012, 486, 43; (b) S. Xu and E. A. Carter, Theoretical Insights into Heterogeneous (Photo)electrochemical $\mathrm{CO}_{2}$ Reduction, Chem. Rev., 2019, 119, 6631; (c) S. Kment, F. Riboni, S. Pausova, L. Wang, L. Wang, H. Han, Z. Hubicka, J. Krysa, P. Schmuki and R. Zboril, Photoanodes based on TiO2 and $\alpha-\mathrm{Fe}_{2} \mathrm{O}_{3}$ for solar water splitting - superior role of $1 \mathrm{D}$ nanoarchitectures and of combined heterostructures, Chem. Soc. Rev., 2017, 46, 3716; (d) W.-H. Wang, Y. Himeda, J. T. Muckerman, G. F. Manbeck and E. Fujita, $\mathrm{CO}_{2}$ Hydrogenation to Formate and Methanol as an Alternative to Photo- and Electrochemical $\mathrm{CO}_{2}$ Reduction, Chem. Rev., 2015, 115, 12936; (e) M. A. Lumley, A. Radmilovic, Y. J. Jang, A. E. Lindberg and K.-S. Choi, Perspectives on the Development of Oxide-Based Photocathodes for Solar Fuel Production, J. Am. Chem. Soc., 2019, 141, 18358. 
4 (a) Z. Wang, X. Mao, P. Chen, M. Xiao, S. A. Monny, S. Wang, M. Konarova, A. Du and L. Wang, Understanding the Roles of Oxygen Vacancies in Hematite-Based Photoelectrochemical Processes, Angew. Chem., Int. Ed., 2019, 58, 1030; (b) Y. Xu, J. Jia, D. Zhong and Y. Wang, Degradation of dye wastewater in a thin-film photoelectrocatalytic (PEC) reactor with slant-placed TiO2/Ti anode, Chem. Eng. J., 2009, 150, 302; (c) W.-W. Zhao, J.-J. Xu and H.-Y. Chen, Photoelectrochemical bioanalysis: the state of the art, Chem. Soc. Rev., 2015, 44, 729; (d) Y. Xu, Y. He, $\mathrm{X}$. Cao, D. Zhong and J. Jia, TiO2/Ti Rotating Disk Photoelectrocatalytic (PEC) Reactor: A Combination of Highly Effective Thin-Film PEC and Conventional PEC Processes on a Single Electrode, Environ. Sci. Technol, 2008, 42, 2612.

5 (a) D. K. Lee, D. Lee, M. A. Lumley and K.-S. Choi, Progress on ternary oxide-based photoanodes for use in photoelectrochemical cells for solar water splitting, Chem. Soc. Rev., 2019, 48, 2126; (b) A. Ambrosi, C. K. Chua, A. Bonanni and M. Pumera, Electrochemistry of Graphene and RelatedMaterials, Chem. Rev., 2014, 114, 7150; (c) Y.-C. Wu, S.-S. Jiang, R.-J. Song and J.-H. Li, A metal- and oxidizingreagent-free anodic para-selective amination of anilines with phenothiazines, Chem. Commun., 2019, 55, 4371; (d) J. H. Kim and J. S. Lee, Elaborately Modified $\mathrm{BiVO}_{4}$ Photoanodes for Solar Water Splitting, Adv. Mater., 2019, 31, 1806938; (e) X. Zhang, X. Wang, X. Yi, J. Ye and D. Wang, Alkali Treatment for Enhanced Photoelectrochemical Water Oxidation on Hematite Photoanode, ACS Sustainable Chem. Eng., 2019, 7, 5420.

6 (a) T. Bach and J. P. Hehn, Photochemical Reactions as Key Steps in Natural Product Synthesis, Angew. Chem., Int. Ed., 2011, 50, 1000; (b) Y.-Q. Zou, F. M. Hörmann and T. Bach, Iminium and enamine catalysis in enantioselective photochemical reactions, Chem. Soc. Rev., 2018, 47, 278; (c) D. Ravelli, S. Protti and M. Fagnoni, Carbon-Carbon Bond Forming Reactions via Photogenerated Intermediates, Chem. Rev., 2016, 116, 9850; (d) Y. Chen, L.-Q. Lu, D.-G. Yu, C.-J. Zhu and W.-J. Xiao, Visible lightdriven organic photochemical synthesis in China, Sci. China: Chem., 2019, 62, 24.

7 (a) P. Xiong and H.-C. Xu, Chemistry with Electrochemically Generated N-Centered Radicals, Acc. Chem. Res., 2019, 52, 3339; (b) H. Wang, X. Gao, Z. Lv, T. Abdelilah and A. Lei, Recent Advances in Oxidative $\mathrm{R}_{1}$ $\mathrm{H} / \mathrm{R}_{2}-\mathrm{H}$ Cross-Coupling with Hydrogen Evolution via Photo-/Electrochemistry, Chem. Rev., 2019, 119, 6769; (c) Y. Jiang, K. Xu and C. Zeng, Use of Electrochemistry in the Synthesis of Heterocyclic Structures, Chem. Rev., 2018, 118, 4485; (d) K. D. Moeller, Using Physical Organic Chemistry To Shape the Course of Electrochemical Reactions, Chem. Rev., 2018, 118, 4817; (e) C. Ma, P. Fang and T.-S. Mei, Recent Advances in $\mathrm{C}-\mathrm{H}$ Functionalization Using Electrochemical Transition Metal Catalysis, ACS Catal., 2018, 8, 7179; (f) Y.-C. Wu, S.-S. Jiang, S.-Z. Luo, R.-J. Song and J.-H. Li, Transition-metal- and oxidant-free directed anodic $\mathrm{C}-\mathrm{H}$ sulfonylation of $\mathrm{N}, \mathrm{N}$-disubstituted anilines with sulfinates, Chem. Commun., 2019, 55, 8995; (g) Y. Yu, P. Guo, J.-S. Zhong, Y. Yuan and K.-Y. Ye, Merging photochemistry with electrochemistry in organic synthesis, Org. Chem. Front., 2020, 7, 131.

8 (a) S. Chen, R. Wojcieszak, F. Dumeignil, E. Marceau and S. Royer, How Catalysts and Experimental Conditions Determine the Selective Hydroconversion of Furfural and 5-Hydroxymethylfurfural, Chem. Rev., 2018, 118, 11023; (b) X. Kong, Y. Zhu, Z. Fang, J. A. Kozinski, I. S. Butler, L. Xu, H. Song and X. Wei, Catalytic conversion of 5-hydroxymethylfurfural to some value-added derivatives, Green Chem., 2018, 20, 3657.

9 H. G. Cha and K.-S. Choi, Combined biomass valorization and hydrogen production in a photoelectrochemical cell, Nat. Chem., 2015, 7, 328.

10 T. Li, T. Kasahara, J. He, K. E. Dettelbach, G. M. Sammis and C. P. Berlinguette, Photoelectrochemical oxidation of organic substrates in organic media, Nat. Commun., 2017, 8, 390.

11 (a) H. Tateno, Y. Miseki and K. Sayama, Photoelectrochemical Oxidation of Benzylic Alcohol Derivatives on $\mathrm{BiVO}_{4} / \mathrm{WO}_{3}$ under Visible Light Irradiation, ChemElectroChem, 2017, 4, 3283; (b) A. W. Harris, O. Yehezkeli, G. R. Hafenstine, A. P. Goodwin and J. N. Cha, Light-Driven Catalytic Upgrading of Butanol in a Biohybrid Photoelectrochemical System, ACS Sustainable Chem. Eng., 2017, 5, 8199.

12 (a) S. Rej, Y. Ano and N. Chatani, Bidentate Directing Groups: An Efficient Tool in $\mathrm{C}-\mathrm{H}$ Bond Functionalization Chemistry for the Expedient Construction of $\mathrm{C}-\mathrm{C}$ Bonds, Chem. Rev., 2020, 120, 1788; (b) X.-H. Ouyang, R.-J. Song and J.-H. Li, Developments in the Chemistry of $\alpha$-Carbonyl Alkyl Bromides, Chem. - Asian J., 2018, 13, 2316.

13 H. Tateno, S. Iguchi, Y. Miseki and K. Sayama, PhotoElectrochemical $\mathrm{C}-\mathrm{H}$ Bond Activation of Cyclohexane Using a $\mathrm{WO}_{3}$ Photoanode and Visible Light, Angew. Chem., Int. Ed., 2018, 57, 11238.

14 D. S. Choi, H. Lee, F. Tieves, Y. W. Lee, E. J. Son, W. Zhang, B. Shin, F. Hollmann and C. B. Park, Bias-Free In Situ $\mathrm{H}_{2} \mathrm{O}_{2}$ Generation in a Photovoltaic-Photoelectrochemical Tandem Cell for Biocatalytic Oxyfunctionalization, ACS Catal., 2019, 9, 10562.

15 P. Lenden, D. A. Entwistle and M. C. Willis, An Alkyne Hydroacylation Route to Highly Substituted Furans, Angew. Chem., Int. Ed., 2011, 50, 10657.

16 H. Tateno, Y. Miseki and K. Sayama, Photoelectrochemical dimethoxylation of furan via a bromide redox mediator using a $\mathrm{BiVO}_{4} / \mathrm{WO}_{3}$ photoanode, Chem. Commun., 2017, 53, 4378.

17 (a) G. S. Sauer and S. Lin, An Electrocatalytic Approach to the Radical Difunctionalization of Alkenes, ACS Catal., 2018, 8, 5175; (b) C. Wan, R.-J. Song and J.-H. Li, Electrooxidative 1,2-Bromoesterification of Alkenes with Acids and N-Bromosuccinimide, Org. Lett., 2019, 21, 2800; (c) M. D. Kärkäs, Electrochemical strategies for $\mathrm{C}-\mathrm{H}$ functionalization and $\mathrm{C}-\mathrm{N}$ bond formation, Chem. Soc. Rev., 2018, 47, 5786. 
18 L. Zhang, L. Liardet, J. Luo, D. Ren, M. Grätzel and X. Hu, Photoelectrocatalytic arene $\mathrm{C}-\mathrm{H}$ amination, Nat. Catal., 2019, 2, 366.

19 (a) M. A. Shameem and A. Orthaber, Organophosphorus Compounds in Organic Electronics, Chem. - Eur. J., 2016, 22, 10718; (b) L. Chen, Y.-X. Zou, X.-Y. Liu and X.-J. Gou, Dehydrative Cross-Coupling and Related Reactions between Alcohols $(\mathrm{C}-\mathrm{OH})$ and $\mathrm{P}(\mathrm{O})-\mathrm{H}$ Compounds for $\mathrm{C}-\mathrm{P}$ Bond Formation, Adv. Synth. Catal., 2019, 361, 3490.
20 J.-H. Wang, X.-B. Li, J. Li, T. Lei, H.-L. Wu, X.-L. Nan, C.-H. Tung and L.-Z. Wu, Photoelectrochemical cell for P$\mathrm{H} / \mathrm{C}-\mathrm{H}$ cross-coupling with hydrogen evolution, Chem. Commun., 2019, 55, 10376.

21 M. Gong, J. K. Kim, X. Zhao, Y. Li, J. Zhang, M. Huang and Y. Wu, Visible-light-induced $\alpha$-oxyamination of 1,3-dicarbonyls with TEMPO via a photo(electro)catalytic process applying a DSSC anode or in a DSSC system, Green Chem., 2019, 21, 3615. 